\title{
A treatment algorithm for the management of cervical spine fractures and deformity in patients with ankylosing spondylitis
}

\author{
Adam S. Kanter, M.D., ${ }^{1}$ Michael Y. Wang, M.D., ${ }^{2}$ And Praveen V. Mummaneni, M.D. ${ }^{1}$ \\ ${ }^{1}$ Department of Neurosurgery, University of California, San Francisco, California; \\ and ${ }^{2}$ Department of Neurosurgery, University of Miami, Florida
}

\begin{abstract}
Object. Patients with ankylosing spondylitis (AS) who present with cervical spine fractures represent a unique challenge to spine surgeons. These injuries often result in neurological deficits that necessitate early and aggressive surgical management with posterior and/or anterior fixation. The authors introduce a clinical problem-solving algorithm to assist in the surgical management of instability and deformity in this exigent patient population.

Methods. Thirteen patients with AS and fractures of the cervical spine were radiographically evaluated to determine if spinal realignment was obtainable with cervical manipulation or traction. Seven patients had flexible deformities that were stabilized with either anterior or posterior fixation only, and 6 patients had fixed deformities and required circumferential anterior-posterior instrumentation. All patients were observed for neurological outcome, radiographic evidence of bone fusion, and complications.

Results. With the use of the authors' treatment algorithm, all patients were able to achieve satisfactory spinal realignment and bone fusion; $92 \%$ of patients achieved postoperative stability or improvement in Nurick and modified Japanese Orthopaedic Association scale scores. One patient experienced neurological deterioration following surgery, and 1 patient died at an acute rehabilitative facility following discharge.

Conclusions. Patients with AS are highly susceptible to extensive neurological injury and spinal deformity after sustaining cervical fractures from even minor traumatic forces. These injuries are uniquely complex in nature and require considerable scrutiny and aggressive surgical management to optimize spinal stability and functional outcomes. The authors' clinical problem-solving algorithm will assist spine surgeons in providing optimal care in this difficult population. (DOI: $10.3171 /$ FOC/2008/24/1/E11)
\end{abstract}

KEY WORDS • ankylosing spondylitis • cervical • deformity • fracture • kyphosis

A NKYLOSING spondylitis is a seronegative, progressive, systemic, inflammatory rheumatic spondyloarthropathy mainly affecting the spine and sacroiliac joints. Ankylosing spondylitis is the third most common arthritic condition in the United States and involves an $H L A-B 27$ genetic predisposition in the majority of cases. ${ }^{7,45}$ The disease is characterized by a diffuse inflammatory reaction resulting in ossification of spinal ligaments, joints, and intervertebral discs. Over time, the once dynamic and flexible spinal column becomes a rigid and deformed lever arm, increasingly susceptible to major traumatic injury from minor forces. ${ }^{6,12,33}$ This leads to decreased functionality and progressive osteoporosis thus increasing the risk of fracture and deformity. ${ }^{5,14,25}$

Patients with AS represent a unique challenge to spine

Abbreviations used in this paper: AS = ankylosing spondylitis; $\mathrm{ASF}$ = anterior segmental fixation; $\mathrm{CT}=$ computed tomography; ICBG = iliac crest bone graft; $\mathrm{mJOA}=$ modified Japanese Orthopaedic Association; PSF = posterior segmental fixation. surgeons when presenting with a cervical spine fracture; the majority of these fractures occur at the level of the intervertebral disc and result in anatomic displacement and instability. ${ }^{18,19,22,31}$ These injuries often result in neurological deficits that necessitate early and aggressive surgical management with posterior and/or anterior fixation techniques to enable neural decompression, spinal stability, and optimal functionality. ${ }^{6,13}$

Several reports have been published describing an array of surgical techniques to treat these fractures and their resulting deformities, ${ }^{10,11,16,43}$ yet no standardized treatment algorithm exists that approaches this challenging pathological entity in a systematic, logical, and concise manner. We aim to introduce a clinical problem-solving algorithm that incorporates both neurological status and spinal deformity variables to establish optimal surgical management methodically in this exigent patient population.

\section{Clinical Material and Methods}

We retrospectively reviewed the cases in a series of pa- 


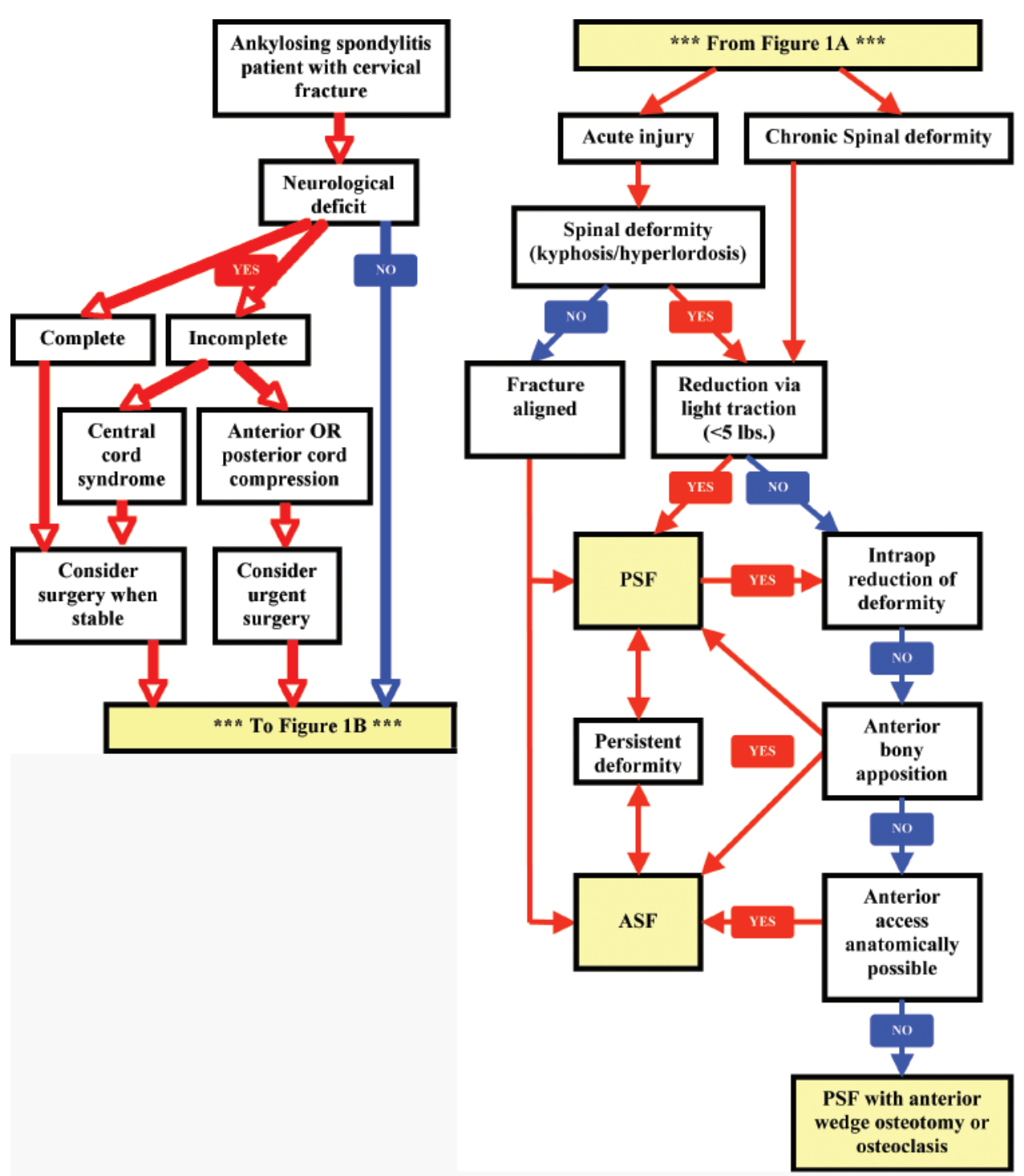

FIG. 1. Flow chart of the proposed algorithm for the management of neurological injury (A) and spinal deformity (B) in patients with $\mathrm{AS}$ and cervical spine fractures.

tients with traumatic cervical fractures and spinal deformity in conjunction with AS who were treated by 2 spine surgeons (P. M. and M. W.) over a 5-year period (20032007). Thirteen patients ( 9 men and 4 women) between the ages of 47 and 83 years (mean 60.4) were included in this cohort.

The problem-solving algorithm illustrated in Fig. 1 was utilized to determine surgical management decisions. Fracture site and pattern, facet pathology, degree of dislocation, cord compression, and deformity were noted. Neurological deficits were classified according to the $\mathrm{mJOA}^{3}$ and Nurick scales. ${ }^{30}$ Surgical urgency was determined by neurological status; patients with incomplete injuries with spinal cord compression were treated urgently (within 24 hours) and those with complete and central cord injuries were stabilized medically and treated with delayed surgery.

All patients were evaluated radiographically with plain films, CT, and magnetic resonance imaging studies. Com- puted tomography scans were used to elucidate the bone detail of the fracture, deformity, and surrounding fixation sites, and magnetic resonance imaging studies to provide ligamentous detail and reveal any complicating factors that might mitigate or amplify surgical urgency (such as an epidural hematoma). Radiography was used to determine if spinal realignment was attainable with gentle cervical manipulation. Acutely injured patients without significant spinal deformity were treated with ASF or PSF, depending on fracture location. Acutely injured patients with spinal deformity, and all patients with delayed injuries, underwent light cervical traction-reduction measures to optimize spinal alignment prior to surgical intervention.

Patients with fractures that could be successfully reduced with light traction underwent PSF, whereas those whose fractures did not reduce required intraoperative reduction measures. The patients in the latter category with anterior bone apposition received an anterior approach for spinal 
TABLE 1

Summary of clinical data obtained in 13 patients with $A S$ and cervical spine fractures with deformity

\begin{tabular}{ccll}
\hline \hline $\begin{array}{c}\text { Case } \\
\text { No. }\end{array}$ & $\begin{array}{c}\text { Age } \\
\text { (yrs), Sex }\end{array}$ & $\begin{array}{c}\text { Fracture } \\
\text { Site }\end{array}$ & $\begin{array}{c}\text { Type of } \\
\text { Deformity }\end{array}$ \\
\hline 1 & $81, \mathrm{M}$ & $\mathrm{C} 6-7$ & acute \\
2 & $55, \mathrm{M}$ & $\mathrm{C} 5-6$ & acute \\
3 & $47, \mathrm{~F}$ & $\mathrm{C} 4-5$ & acute \\
4 & $53, \mathrm{~F}$ & $\mathrm{C} 7-\mathrm{T} 1$ & acute \\
5 & $49, \mathrm{~F}$ & $\mathrm{C} 6-7$ & acute \\
6 & $53, \mathrm{M}$ & $\mathrm{C} 7-\mathrm{T} 1$ & chronic \\
7 & $60, \mathrm{~F}$ & $\mathrm{C} 6-7$ & acute \\
8 & $60, \mathrm{M}$ & $\mathrm{C} 6-7$ & chronic \\
9 & $63, \mathrm{M}$ & $\mathrm{C} 6-7 \&$ & chronic \\
& & $\mathrm{C} 7-\mathrm{T} 1$ & \\
10 & $67, \mathrm{M}$ & $\mathrm{C} 7-\mathrm{T} 1$ & acute \\
11 & $66, \mathrm{M}$ & $\mathrm{C} 7-\mathrm{T} 1$ & acute \\
12 & $83, \mathrm{M}$ & $\mathrm{C} 7-\mathrm{T} 1$ & acute \\
13 & $48, \mathrm{M}$ & $\mathrm{C} 6-7$ & acute \\
\hline
\end{tabular}

realignment if the anatomical access permitted, otherwise a posterior approach was performed followed by either anterior wedge osteotomy or osteoclasis and PSF.

Patients were monitored for neurological outcome, radiographic fusion, and complications. Complications were categorized into general (such as infection, dysphagia, or death) and surgical (such as instrumentation failure) subtypes. Postoperative follow-up examinations were performed at intervals of 6 weeks, 6 months, and annually thereafter, with radiographic evaluations including CT scans obtained immediately postoperatively and again at the 6 and 12 month follow-up examinations. Dynamic flexion-extension radiographs were performed at all follow-up visits.

\section{Results}

Clinical data are summarized in Table 1 . Ten (77\%) of the 13 fractures were acute injuries and $3(23 \%)$ were chronic in nature. Twelve fractures $(92 \%)$ involved 1 cer-
TABLE 2

Summary of surgical data in 13 patients with AS and cervical spine fractures with deformity*

\begin{tabular}{|c|c|c|c|}
\hline $\begin{array}{l}\text { Case } \\
\text { No. }\end{array}$ & $\begin{array}{c}\text { Surgical } \\
\text { Approach }\end{array}$ & $\begin{array}{c}\text { Fixation } \\
\text { Level }\end{array}$ & $\begin{array}{c}\text { Graft } \\
\text { Materials }\end{array}$ \\
\hline 1 & $\mathrm{~A} / \mathrm{P}$ & $\mathrm{C} 4-\mathrm{T} 2$ & fibula \& local bone \\
\hline 2 & $\mathrm{~A} / \mathrm{P}$ & C3-6 & fibula \& local bone \\
\hline 3 & $\mathrm{~A} / \mathrm{P}$ & C3-6 & fibula \& ICBG \\
\hline 4 & $\mathrm{P}$ & $\mathrm{C} 4-\mathrm{T} 4$ & ICBG \\
\hline 5 & P/A & $\mathrm{C} 4-\mathrm{T} 3$ & PEEK \& ICBG \\
\hline 6 & A & C7-T1 & PEEK \& local bone \\
\hline 7 & $\mathrm{~A} / \mathrm{P}$ & $\mathrm{C} 5-\mathrm{T} 2$ & PEEK \& local bone \\
\hline 8 & $\mathrm{~A} / \mathrm{P}$ & $\mathrm{C} 4-\mathrm{T} 2$ & fibula \& local bone \\
\hline 9 & $\mathrm{P}$ & C6-T3 & local bone \\
\hline 10 & $\mathrm{P}$ & $\mathrm{C} 4-\mathrm{T} 2$ & ICBG \\
\hline 11 & $\mathrm{P}$ & $\mathrm{C} 6-\mathrm{T} 2$ & ICBG \\
\hline 12 & $\mathrm{P}$ & $\mathrm{C} 3-\mathrm{T} 2$ & local bone \\
\hline 13 & $\mathrm{P}$ & $\mathrm{C} 4-\mathrm{T} 2$ & ICBG \\
\hline
\end{tabular}

$* \mathrm{~A}=$ anterior only; $\mathrm{P}=$ posterior only; $\mathrm{A} / \mathrm{P}=2$ stages: anterior, then posterior; $\mathrm{P} / \mathrm{A}=2$ stages: posterior, then anterior. Abbreviation: $\mathrm{PEEK}=$ polyetheretherketone.

vical segment, and $1(8 \%)$ involved 2 levels. The most frequently injured levels were C6-7 and C7-T1 (in 85\% of patients). One patient (8\%) suffered a concomitant epidural hematoma necessitating urgent surgical evacuation in addition to the stabilizing procedure.

Surgical data are summarized in Table 2. Six patients $(46 \%)$ with flexible deformities were stabilized with posterior fixation only, and 1 patient $(8 \%)$ underwent a sole anterior fixation procedure. The remaining 6 patients received circumferential fixation, 5 (38\%) via an anterior approach followed by posterior instrumentation, and $1(8 \%)$ via posterior stabilization prior to anterior fixation. An average of 5.6 segments were instrumented in each case with harvesting of ICBG material in 6 patients $(46 \%)$; all others received autogenous local bone graft obtained from the spinous processes and lamina. A fibular interbody allograft was utilized in 4 of the anterior procedures, polyetheretherketone cages filled with morselized autogenous bone was
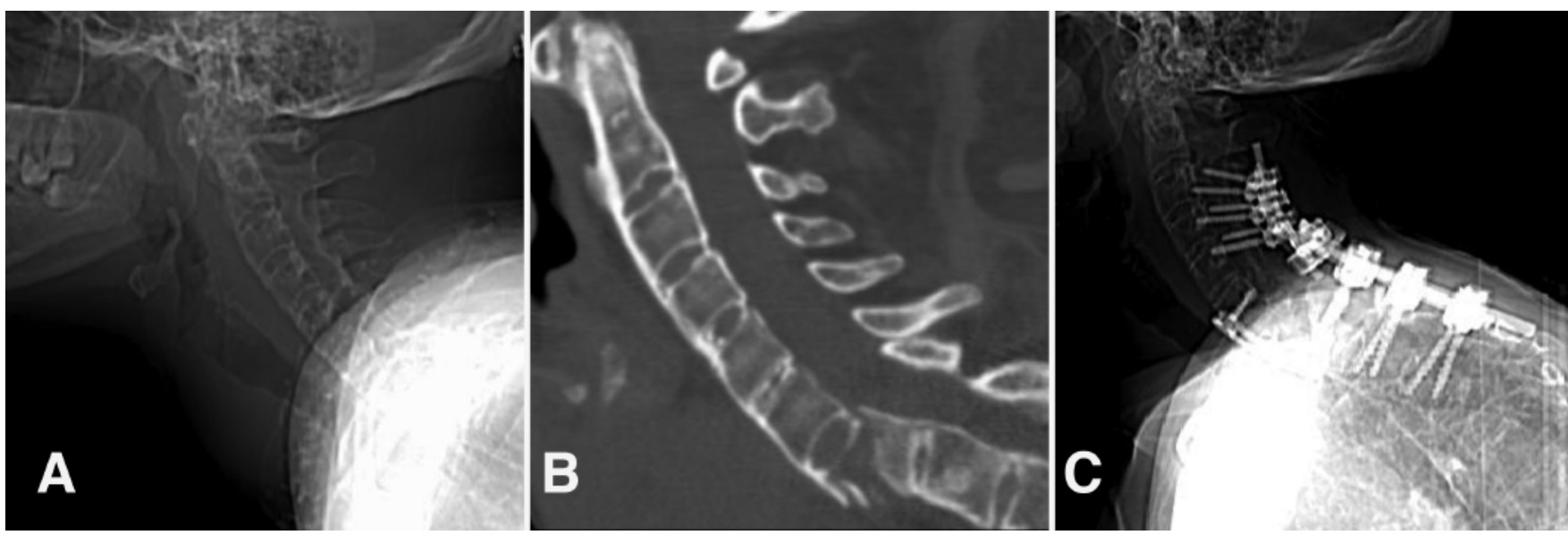

FIG. 2. Preoperative plain radiograph (A) and CT scan (B) showing C6-7 fracture dislocation in the patient in Case 5. Postoperative plain radiography study obtained at the 1-year follow-up examination (C) showing successful spinal realignment and fusion with anterior-posterior instrumentation. 
used in 3. Representative pre- and postoperative imaging studies obtained in a patient who underwent typical anterior-posterior fixation are shown in Fig. 2.

Figure 3A and B graphically depicts pre- and postoperative neurological status as classified using the Nurick ${ }^{30}$ and mJOA scales. ${ }^{1,3}$ Twelve of the 13 patients either maintained stability or experienced improvement in their neurological deficits after surgical intervention. One patient suffered deterioration in neurological status, climbing 1 level on the Nurick scale and dropping 1 level on mJOA classification. The remaining patients improved an average of 0.9 on the mJOA scale ( 8.8 to 9.7 ). One patient improved by 5 grades, 2 patients by 3 grades, and 2 patients by 1 grade. Seven patients' conditions remained unchanged.

General and surgical complications are summarized in Table 3. Five (38\%) of the 13 patients suffered sequelae. Two patients required repeated operations because of hardware failure (screw pullout and graft/plate migration; Fig. 4). One experienced severe dysphagia secondary to intraoperative esophageal manipulation, which required the placement of a percutaneous endoscopic gastrostomy tube for a 2-month period until adequate improvement in swallowing allowed for its removal. One patient suffered permanent loss of vision following surgery in the prone position, and 1 patient died of an aspiration event in a rehabilitation facility 2 months postoperatively.

Of the 12 surviving patients, 10 achieved radiographic fusion confirmed by CT scan (2 patients were lost to radiographic follow up). The average postoperative follow-up period was 12.8 months (range 3-22 months).

\section{Discussion}

In the present study, 13 patients with AS and cervical fractures received treatment according to the problem-solving algorithm depicted in Fig. 1. There were 4 complications and 1 death, yielding a 38\% complication and mortality rate in this challenging patient population; this rate is similar to the rates reported in other series. ${ }^{13,14,27}$

Neurological deterioration and/or spinal deformity are indications for surgical realignment, fixation, and/or spinal decompression. In the absence of deficit or deformity, attempts have been made to manage the care of these patients nonsurgically, yielding adverse outcomes and neurological sequelae. $1,4,8,12,22,31,32,37$ Progressive neurological injury secondary to delayed dislocation at the original fracture site has been found in as many as $60 \%$ of cases managed conservatively. ${ }^{4,14,48}$ Other complications following nonsurgical efforts include infection, skin ulceration (from pressure

\section{A}

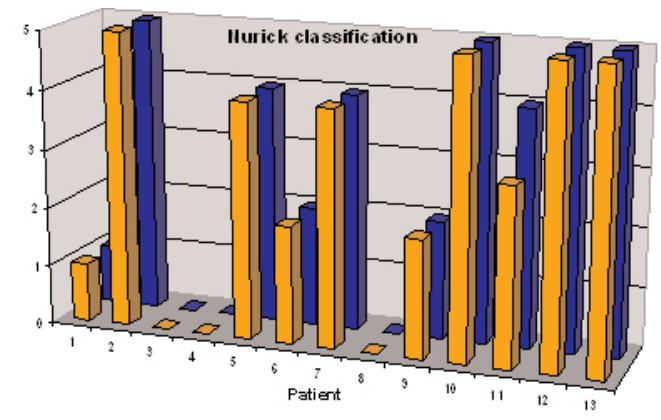

Nurick grade:

0 Root symptoms only

1 Signs of cord compression but normal gait

2 G ait difficulties but fully employed

3 Can walk unassisted but gait difficulties prevent employment

4 Unable to walk without assistive devices

5 Wheelchair or bed bound

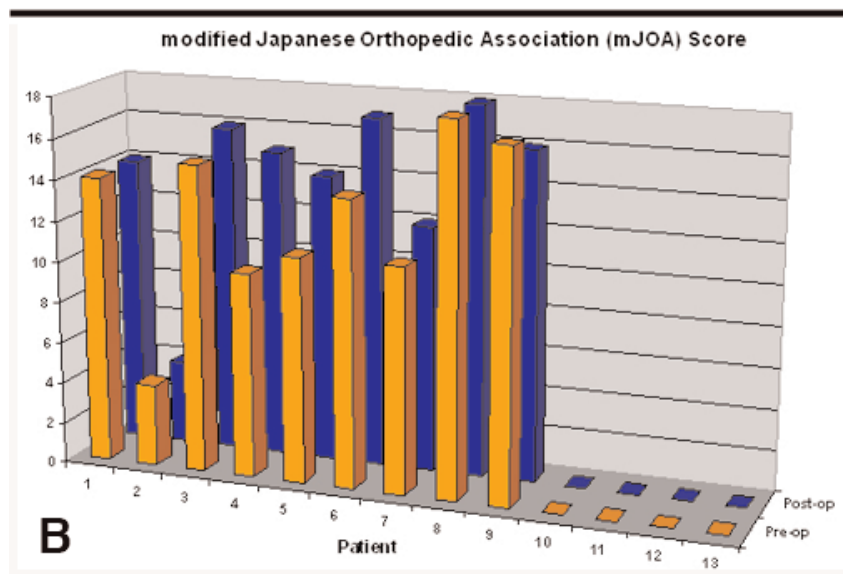

FIG. 3. Bar graphs of pre- and postoperative Nurick grades (A) and mJOA scale scores (B) in 13 patients with AS.

sores under hard collars), fracture nonunion, and pulmonary impairment caused by the intrinsic limitations in chest wall expansion and reduced vital pulmonary capacity in AS patients. ${ }^{2,21,33,34,47}$ For these reasons we recommend surgical fixation measures in all parts of the treatment algorithm. The most frequently injured cervical segments in this series were C6-7 and C7-T1 (in 86\% of patients), a finding congruent with other studies in the literature, , $8,20-22,28,31,46$ and commonly necessitating fusion across the cervicothoracic junction. The authors of several studies have reported realignment and stability of cervical fractures with fixation approach dependent on fracture site and loca-

TABLE 3

Summary of complications*

\begin{tabular}{rll}
\hline \hline Case No. & \multicolumn{1}{c}{ Complication } & \multicolumn{1}{c}{ Action Taken } \\
\hline 1 & $\begin{array}{l}\text { patient died in rehabilitation } \\
\text { posterior hardware failure (screw pullout), } \\
\text { wound infection, \& incarcerated bowel }\end{array}$ & $\begin{array}{l}\text { none } \\
\text { repeated operation, wound washout, \& laparotomy }\end{array}$ \\
7 & $\begin{array}{l}\text { interbody graft \& plate migration secondary to new fracture } \\
\text { at inferior aspect of construct }\end{array}$ & $\begin{array}{l}\text { repeated operation, additional corpectomy w/ } \\
\text { expansion of interbody graft \& plate }\end{array}$ \\
9 & $\begin{array}{l}\text { dysphagia secondary to esophageal manipulation } \\
\text { blindness following prone positioning surgery }\end{array}$ & $\begin{array}{l}\text { PEG placement for 2 months } \\
\text { none }\end{array}$ \\
\hline
\end{tabular}

*Abbreviation: PEG = percutaneous endoscopic gastrostomy. 


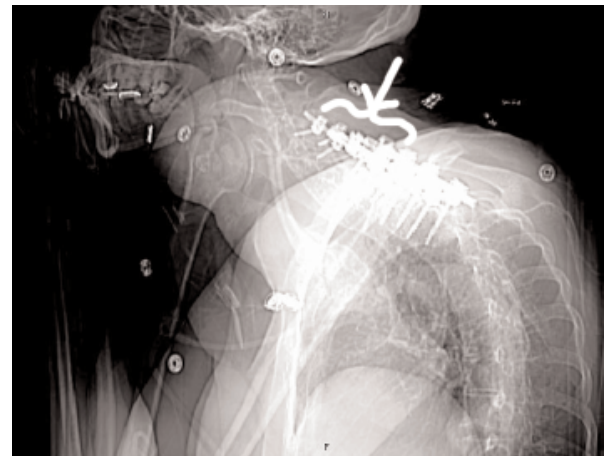

FIG. 4. Plain $\mathrm{x}$-ray films revealing posterior instrumentation failure (screw pullout) obtained in the patient in Case 5. The patient subsequently underwent $360^{\circ}$ circumferential fixation.

tion; anterior fractures were treated anteriorly, posterior fractures posteriorly, and circumferential 3-column injuries via $360^{\circ}$ fixation. Single-stage $360^{\circ}$ fusion in the medically stable patient avoids the added risk of multiple anesthetic interventions, although at the cost of a slightly higher risk of infection. ${ }^{41}$

Regardless of surgical technique, patients with AS are predisposed to a dramatically increased risk of surgical complications as evidenced by the present surgical series and others. ${ }^{1,14-16}$ These complications include an increased risk of epidural hematoma and generalized bleeding ${ }^{17,44}$ and instrumentation pullout from osteoporotic bone subjected to long lever arm forces. ${ }^{5,15,26,36}$ Implant failure occurred in 2 patients $(15 \%)$, both of whom required repeated operations for hardware replacement. Repeated operation imparts additional risk of complications given that it often entails expansion of instrumentation to at least 1 additional uninjured segment. ${ }^{29}$

Attempts to realign the displaced cervical spine in patients with AS must initially be focused on restoring the original sagittal curvature of the patient's diseased state prior to the fracture. We recommend that surgical decompression be performed urgently in patients with incomplete cord injuries, whereas those with complete or central cord injuries can be treated in a delayed fashion (Fig. 1A).

Acute injuries without spinal deformity can be managed with either ASF or PSF, depending on the injury site. Patients who present with spinal deformity, as well as those with delayed injuries, should be placed in light cervical traction $(<5 \mathrm{lbs})$ to attempt fracture reduction and spinal realignment. We typically avoid traction weights over $5 \mathrm{lbs}$ because sudden, uncontrolled distraction of the cervical spine may occur with heavier weights. If anterior bone apposition is accomplished, PSF can be performed, with a second stage ASF if there is persistent spinal deformity. If anatomic access is limited because of a pronounced deformity (such as chin on chest), prolonged cervical traction (several days in an intensive care unit with low traction weight) and/or an anterior wedge release via osteotomy or osteoclasis can be performed, followed by PSF to restore craniocervical alignment (Fig. 1B). This osteotomy technique has been previously reported by the senior author, ${ }^{27}$ and its functional significance includes restoration of natural horizontal gaze as emphasized by Suk et al. ${ }^{42}$ and others. ${ }^{13}$
If cervical osteotomies are required, they are preferentially performed at $\mathrm{C}-7$ and $\mathrm{T}-1$ due to the absence of the vertebral artery in the foramen transversarium and the enlarged spinal canal at these levels. Additionally, if iatrogenic spinal cord injury did occur at or below C-7, at least partial upper extremity function would be preserved. Simmons ${ }^{39,40}$ initially described the cervical posterior wedge osteotomy technique that he performed with the patient in the awake sitting position without posterior instrumentation. Mehdian and colleagues ${ }^{25}$ were among the first to expand on Simmons' technique with the incorporation of posterior instrumentation to avoid sudden spinal subluxation during the correction maneuver and to avoid the use of postoperative halo immobilization.

McMaster $^{24}$ reported on his experience in performing 15 C7-T1 wedge osteotomies in patients with AS. He obtained a mean kyphosis correction of $54^{\circ}$ with restoration of lordosis in all cases, but at the expense of a relatively high complication rate including 2 patients with $\mathrm{C}-8$ nerve root palsies, 4 with progressive subluxations, 2 with pseudoarthroses, and 1 patient with quadriparesis. Several authors of more recent studies have reported similar findings with unique variations in technique to minimize complications and maximize deformity correction. These include the use of transcranial electrical stimulated motorevoked potential monitoring ${ }^{23}$ and controlled intraoperative extension osteotomy on a Jackson table. ${ }^{9}$

Four patients in the present study suffered fractures that were complicated by delayed chin-on-chest deformities. Two patients were successfully extended with preoperative awake halo traction (Fig. 5), a third underwent reduction with manual traction in the operating room while in a state of general anesthesia with neurological monitoring, and the fourth received bone osteoclasis from C6-T1. Two patients subsequently underwent PSF and 2 patients underwent $360^{\circ}$ fusion with successful deformity correction and fusion without neurological sequelae.

Injuries that cannot be reduced with traction preoperatively can be addressed via open reduction maneuvers (with or without with osteotomies). Open reduction can be performed with spinous process leverage traction on the dislocated facet posteriorly, or with bur excision of the facet complex if gentle traction is unsuccessful. ${ }^{38}$ Rigid internal fixation is then performed with the goal of limiting fused levels, but not at the expense of a solid construct. In patients with AS this often involves the inclusion of several segments cephalad and caudal to the fracture site. The present study included an average of 5.6 levels of spinal fusion per patient (range 2-8 levels).

Posterior instrumentation in the cervical spine is usually placed into the lateral mass complex secondary to the small pedicle size and encasement of the often aberrant vertebral artery. Thoracic spine hardware is typically placed in a transpedicular fashion under fluoroscopic guidance. Given the anatomic bone distortion secondary to the underlying disease process, the typical landmarks are often obscured, making hardware placement a unique challenge in patients with AS. Detailed knowledge and familiarity with lateral mass and pedicle anatomy is essential for the extrapolation of limited recognizable landmarks during hardware placement and trajectory infiltration.

Posterior instrumentation must be supplemented with bone graft material to insure construct and fusion longevi- 

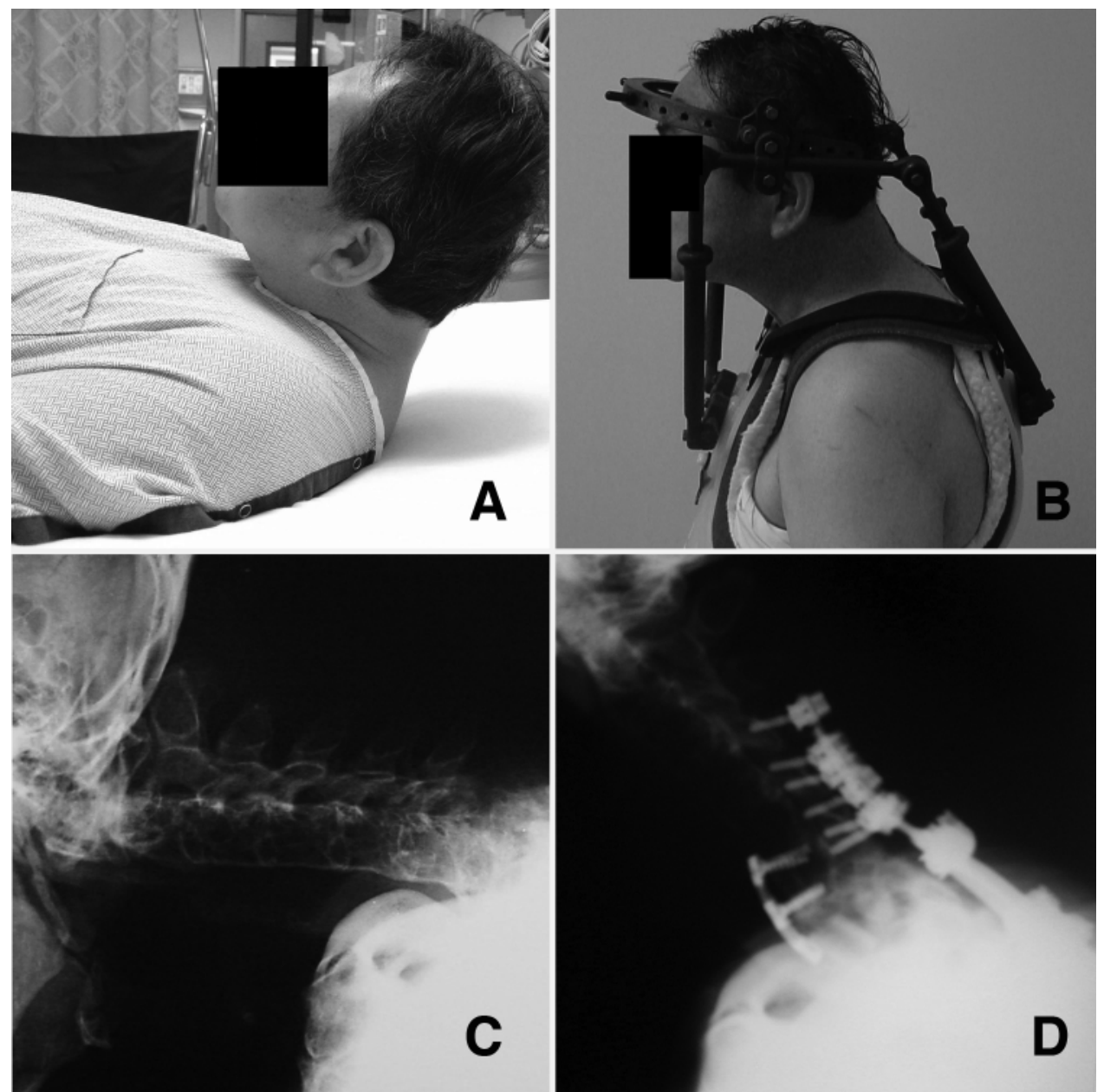

FIG. 5. Images obtained in the patient in Case 8 with C6-7 fracture and chin-on-chest deformity. Photograph obtained at admission (A) and after correction with halo traction (B). Preoperative (C) and postoperative (D) plain radiography after anterior-posterior C-7 corpectomy and C4-T2 posterior fixation.

ty. This is typically performed with local bone harvested from the spinous processes or lamina, rib autograft, or iliac crest autograft. Several series have documented successful fusions with the use of the aforementioned materials, although ICBG has historically shown the greatest structural integrity and remains the gold standard for successful fusion supplementation. Additionally, the use of ICBG avoids the potential complications of rib graft harvesting, which include damage to the neurovascular bundle and pleural cavity. $1,18,35$ However, the ICBG harvest site is commonly identified as a significant pain source in the immediate postoperative period, thus limiting early mobilization and increasing the risk of stasis sequelae (such as deep venous thrombosis). In the present study, 6 patients (46\%) underwent ICBG harvesting for fusion supplementation. To date, progressive bone fusion on CT scanning has been revealed in all patients with $>6$ months of follow-up, but long-term follow-up is needed to ascertain the efficacy of ICBG over alternative graft substitutes.

\section{Conclusions}

Patients with AS are highly susceptible to extensive neurological injury and spinal deformity after cervical frac- tures caused by even minor traumatic forces. These injuries are uniquely complex in nature and require considerable scrutiny and aggressive surgical management to optimize spinal stability and functional outcomes. We propose the aforementioned clinical problem-solving algorithm to systematically assist spine surgeons in their efforts to provide optimal surgical management in this difficult patient population.

\section{References}

1. Alaranta H, Luoto S, Konttinen YT: Traumatic spinal cord injury as a complication to ankylosing spondylitis. An extended report. Clin Exp Rheumatol 20:66-68, 2002

2. Apple DF Jr, Anson C: Spinal cord injury occurring in patients with ankylosing spondylitis: a multicenter study. Orthopedics 18:1005-1011, 1995

3. Benzel EC, Lancon J, Kesterson L, Hadden T: Cervical laminectomy and dentate ligament section for cervical sponylotic myelopathy. J Spinal Disord 4:286-295, 1991

4. Bessant R, Keat A: How should clinicians manage osteoporosis in ankylosing spondylitis? J Rheumatol 29:1511-1519, 2002

5. Bronson WD, Walker SE, Hillman LA, Keisler D, Hoyt T, Allen SH: Bone mineral density and biochemical markers of bone metabolism in ankylosing spondylitis. J Rheumatol 25:929-935, 1998 
6. Broom MJ, Raycroft JF: Complications of fractures of the cervical spine in ankylosing spondylitis. Spine 13:763-766, 1988

7. Calin A, Fries JF: Striking prevalence of ankylosing spondylitis in "healthy" w27 positive males and females. N Engl J Med 293: 835-839, 1975

8. Caspar W, Barbier DD, Klara PM: Anterior cervical fusion and Caspar plate stabilization for cervical trauma. Neurosurgery 25: 491-502, 1989

9. Chin KR, Ahn J: Controlled cervical extension osteotomy for ankylosing spondylitis utilizing the Jackson operating table: technical note. Spine 32:1926-1929, 2007

10. Cooper PR, Cohen A, Rosiello A, Koslow M: Posterior stabilization of cervical spine fractures and subluxations using plates and screws. Neurosurgery 23:300-306, 1988

11. Cornefjord M, Alemany M, Olerud C: Posterior fixation of subaxial cervical spine fractures in patients with ankylosing spondylitis. Eur Spine J 14:401-408, 2005

12. Detwiler KN, Loftus CM, Godersky JC, Menezes AH: Management of cervical spine injuries in patients with ankylosing spondylitis. J Neurosurg 72:210-215, 1990

13. Deutsch H, Haid Jr RW: Cervical ankylosing spondylitis, in Mummaneni PV, Lenke LG, Haid Jr RW (eds): Spinal Deformity: A Guide to Surgical Planning and Management. St. Louis: Quality Medical Publishing, 2008, pp 307-330

14. Einsiedel T, Schmelz A, Arand M, Wilke HJ, Gebhard F, Hartwig $\mathrm{E}$, et al: Injuries of the cervical spine in patients with ankylosing spondylitis: experience at two trauma centers. J Neurosurg Spine 5:33-45, 2006

15. El Maghraoui A, Borderie D, Charruau B, Edouard R, Dougados M, Roux C: Osteoporosis, body composition, and bone turnover in ankylosing spondylitis. J Rheumatol 26:2205-2209, 1999

16. El Masry MA, Badaway WS, Chan D: Combined anterior and posterior stabilization for treating an unstable cervical spine fracture in a patient with long standing ankylosing spondylitis. Injury 35:1064-1067, 2004

17. Fitt G, Hennessey O, Thomas D: Case report 709: Transverse fracture with epidural and small paravertebral hematoma in a patient with ankylosing spondylitis. Skeletol Radiol 21:61-63, 1992

18. Fox MW, Onofrio BM, Kilgore JE: Neurological complications of ankylosing spondylitis. J Neurosurg 78:871-878, 1993

19. Graham B, Van Peteghem PK: Fractures of the spine in ankylosing spondylitis. Diagnosis, treatment, and complications. Spine 14:803-807, 1987

20. Harding JR, McCall IW, Park WM, Jones BF: Fracture of the cervical spine in ankylosing spondylitis. Br J Radiol 58:3-7, 1985

21. Hossain M, McLean A, Fraser MH: Outcome of halo immobilization of 104 cases of cervical spine injury. Scott Med J 49:90-92, 2004

22. Hunter T, Dubo H: Spinal fractures complicating ankylosing spondylitis. Ann Intern Med 88:546-549, 1978

23. Langeloo DD, Journee HL, Pavlov PW, de Kleuver M: Cervical osteotomy in ankylosing spondylitis: evaluation of new developments. Eur Spine J 15:493-500, 2006

24. McMaster MJ: Osteotomy of the cervical spine in ankylosing spondylitis. J Bone Joint Surg Br 79:197-203, 1997

25. Mehdian SM, Freeman BJ, Licina P: Cervical osteotomy for ankylosing spondylitis: an innovative variation on an existing technique. Eur Spine J 8:505-509, 1999

26. Mullaji AB, Upadhyay SS, Ho EKW: Bone mineral density in ankylosing spondylitis. DEXA comparison of control subjects with mild and advanced cases. J Bone Joint Surg Br 76: $660-665,1994$

27. Mummaneni PV, Mummaneni VP, Haid RW Jr, Rodts GE Jr, Sasso RC: Cervical osteotomy for the correction of chin-on-chest deformity in ankylosing spondylitis. Technical note. Neurosurg Focus 14(1): E9, 2003

28. Murray GC, Persellin RH: Cervical fracture complicating ankylosing spondylitis: a report of eight cases and review of the literature. Am J Med 70:1033-1041, 1981
29. Naderi S, Alberstone CD, Rupp FW, Benzel EC, Baldwin NG: Cervical spondylotic myelopathy treated with corpectomy: technique and results in 44 patients. Neurosurg Focus 1(6): E4, 1996

30. Nurick $S$ : The pathogenesis of the spinal cord disorder associated with cervical spondylosis. Brain 95:87-100, 1972

31. Olerud C, Frost A, Bring J: Spinal fractures in patients with ankylosing spondylitis. Eur Spine J 5:51-55, 1996

32. Rose KA, Kim WS: The effect of chiropractic care for a 30-yearold male with advanced ankylosing spondylitis: a time series case report. J Manipulative Physiol Ther 26: E1-E9, 2003

33. Rowed DW: Management of cervical spinal cord injury in ankylosing spondylitis: the intervertebral disc as a cause of cord compression. J Neurosurg 77:241-246, 1992

34. Samartzis D, Liu JC: Ankylosing spondylitis, in Batjer HH, Loftus CM (eds): Textbook of Neurological Surgery: Principles and Practice. Philadelphia: Lippincott-Raven, 2002, pp 1713-1723

35. Sawin PD, Traynelis VC, Menezes AH: A comparative analysis of fusion rates and donor-site morbidity for autogenic rib and iliac crest bone grafts in posterior cervical fusions. J Neurosurg 88: 255-265, 1998

36. Shen FH, Samartzis D: Cervical spine fracture in the ankylosing spondylitis patient. J Am Coll Surg 200:632-633, 2005

37. Shen FH, Samartzis D: Successful nonoperative treatment of a three-column thoracic fracture in a patient with ankylosing spondylitis: existence and clinical significance of the fourth column of the spine. Spine 32: E423-E427, 2007

38. Shen FH, Samartzis D: Surgical management of lower cervical spine fracture in ankylosing spondylitis. J Trauma 61: 1005-1009, 2006

39. Simmons EH: The surgical correction of flexion deformity of the cervical spine in ankylosing spondylitis. Clin Orthop Relat Res 86:132-143, 1972

40. Simmons ED, DiStefano RJ, Zheng Y, Simmons EH: Thirty-six years experience of cervical extension osteotomy in ankylosing spondylitis: techniques and outcomes. Spine 31:3006-3012, 2006

41. Slone RM, McEnery KW, Bridwell KH, Montgomery WJ: Fixation techniques and instrumentation used in the cervical spine. Radiol Clin North Am 33:213-232, 1995

42. Suk KS, Kim KT, Lee SH, Kim JM: Significance of chin-brow vertical angle in correction of kyphotic deformity of ankylosing spondylitis patients. Spine 28:2001-2005, 2003

43. Taggard DA, Traynelis VC: Management of cervical spine fractures in ankylosing spondylitis with posterior fixation. Spine 25: 2035-2039, 2000

44. Tetzlaff JE, Yoon HJ, Bell G: Massive bleeding during spine surgery in a patient with ankylosing spondylitis. Can J Anaesth 45:903-906, 1998

45. van der Linden SM, Valkenburg DA, de Jongh BM, Cats A: The risk of developing ankylosing spondylitis in HLA-B27 positive individuals. A comparison of relatives of spondylitis patients with the general population. Arth Rheum 27:241-249, 1984

46. Vosse D, Feldtkeller E, Erlendsson J, Geusens P, van der Linden $\mathrm{S}$ : Clinical vertebral fractures in patients with ankylosing spondylitis. J Rheumatol 31:1981-1985, 2004

47. Weinstein PR, Karpman RR, Gall EP, Pitt M: Spinal cord injury, spinal fractures, and spinal stenosis in ankylosing spondylitis. J Neurosurg 57:609-616, 1982

48. Yilmaz N, Pence S, Kepekci Y, Geyikli I, Ozaslan J: Association of immune function with bone mineral density and biochemical markers of bone turnover in patients with ankylosing spondylitis. Int J Clin Pract 57:681-685, 2003

Manuscript submitted October 24, 2007.

Accepted November 8, 2007.

Address correspondence to: Praveen V. Mummaneni, M.D., University of California, San Francisco Spine Center, 505 Parnassus Ave, M-779, Box 0112, San Francisco, California 94143. email: vmum@aol.com. 